\title{
SEYYİD GAZİ ZAVİYESİ VE YILLIK MERASİMLERİ HAKKINDA
}

\author{
About the Seyyid Gazi Zawiya and Its Annual Ceremonies
}

\section{Über die Zeremonien in dem Seyyid Gazi Sufiwinkel}

\section{Cahit TELCI ${ }^{*}$}

DOI: http://dx.doi.org/10.22520/abked.2016.14.0003

Seyyid Gāzi Zâviyesi Anadolu'da en erken oluşturulan dini merkezlerin başında gelmektedir. Zâviyenin adına kurulmuş olduğu aziz kişi olan Seyyid Gāzi adı ve onun adına oluşturulmuş olan Zâviye XIII. Yüzyıldan bu güne kadar hiç kesintisiz dini bir merkez olma özelliğini muhafaza etmiştir. Zâviye özellikle klasik dönemde Osmanlı Kalenderîliğinin en önemli merkezi olarak dikkat çekmektedir.

Burada yapılmakta olan merasimleri yazılı kaynaklardaki bilgilerle XV. yüzyılın ilk çeyreğinden itibaren takip edebilmekteyiz. Osmanlı kayıtlarında her sene güz eyyamında Seyyid Gäz̨i Mâhiyesi adıyla yapılmakta olan merasimlerden bahsedilmektedir. $\mathrm{Bu}$ merasimler bildiğimiz gibi bazı musiki aletleri de kullanılarak icra edilmekte idi. Merasime katılanlar ya da bunlardan bir kısmı aynı zamanda semah da yapmaktadırlar.

Burada yapılan merasimler elbette Osmanlı dünyasının genel geçer sünni kesimleri ile zaman zaman bazı tartışmaların yaşanmasına da sebebiyet vermektedir. Osmanlı yönetimi, bir taraftan Seyyid Gāzi'yi bir aziz kişi olarak kabul ederek onun adına tesis edilmiş olan Zâviyeye ve orada bulunan dervişlere bazı muafiyetler tanıyıp, dervişlerin kendi şeyhlerini bile seçmelerini mümkün kılarken öte taraftan sünni algının kabul etmediği bazı ritüellerin yerine getirilmesi konusuna cevaz göstermemekte ve bu davranışların men edilmesi iradesini ortaya koymaktadır. Çelişki gibi görünmekle beraber Osmanlı merkez yönetiminin benzer vakalardaki temel yaklaşım kalıbının böyle olduğu ifade edilmelidir.

Doç. Dr., İzmir Kâtip Çelebi Üniversitesi Sosyal ve Beşeri Bilimler Fakültesi Tarih Bölümü. 
Biz küçük çalışmamızda bu iki algıyı ifade eden belgeler ve kaynakları kullanmak suretiyle Zâviyenin Osmanlı dünyasındaki konumuna bir pencere açmaya ve benzer örnekler ile mukayese etmeye çalışacağız.

Anahtar Kelimeler: Seyyid Gazi, Seyyid Gazi Zaviyesi, Yunus Emre, Zaviye, Ritüel,

\begin{abstract}
The Seyyid Gazi zawiya is the leading religious center among the first religious centers formed in Anatolia. The zawiya and the name of Seyyid Gazi, sacred person to whom was dedicated the zawiya, have maintained the characteristic of being a religious center without an interruption since 13th century. The zawiye draws attention, especially in the Classical era, as the most important center of Kalandars in the Ottoman Empire.

With the data from written sources, we can trace back ceremonies practiced in this zawiya to the first half of 15 th century. In the Ottoman records, there are references to the ceremonies practiced every year in the autumn in the name of Seyyid Gazi. As we know, these ceremonies are also performed using some music instruments. In the same time, participants in ceremony or some of them whirl the "semah".

Certainly, ceremonies performed in this place were occasionally causing some discussions with Sunni Muslims who were generally accepted in the Ottoman world. On the one hand, the Ottoman administration granted some exemptions for the zawiya, founded in the name of Seyyid Gazi by accepting him as a sacred person, and for dervishes situated there, and even allowed dervishes to select their own sheikh. But on the other hand, it didn't tolerate some rituals which were not acceptable by Sunni perception and made decision to prohibit these acts. Despite contradiction, it must be pointed out that the Ottoman central administration was taking the same approach in similar cases.

In this short paper, we will try to open a window into the position of the zawiya in the Ottoman world by using documents and sources concerning these two perceptions, and to compare it with similar examples.
\end{abstract}

Key Words: Seyyid Gazi, The Seyyid Gazi Zawiya, Yunus Emre, Zawiye, Ritual, 


\section{ZUSAMMENFASSUNG}

Seyyid Gazi Sufiwinkel (Seyyid Gazi Zaviyesi) zählt unter den ältesten gegründeten religiösen Zentren in Anatolien zu den ersten Adressaten. Sowohl der Name des Heiligen Seyyid Gazi, als auch dieser in seinem Namen gegründete Sufiwinkel konnten vom XIII. Jahrhundert bis in die Gegenwart hinein ihr Wahrzeichen, ein ununterbrochenes Religionszentrum weiterzubestehen, beibehalten. Dieser Sufiwinkel fiel insbesondere in der klassischen Zeit als das wichtigste Zentrum der wandernde Derwisch der Osmanen auf.

Wir können die Praxis der Zeremonien in diesem Sufiwinkel anhand der Informationen in den schriftlichen Quellen ab dem ersten Viertel des XV. Jahrhunderts zurückverfolgen. Osmanische Quellen berichten von Zeremonien, die jedes Jahr im Herbst unter dem Namen "Seyyid Gazi Mâhiyesi” veranstaltet wurden. Soweit uns bekannt ist, wurden diese Zeremonien unter Einsatz von einigen Musikinstrumenten durchgeführt. Die Teilnehmer der Zeremonie oder ein Teil von ihnen tanzte zugleich auch den Semah.

Natürlich gaben die hier praktizierten Zeremonien von Zeit zu Zeit auch Anlass zu einigen Streitigkeiten mit den Mainstream-Vertreten unter den Sunniten der Osmanischen Welt. Einerseits erkannte die osmanische Regierung Seyyid Gazi als einen Heiligen an und sicherte dem in seinem Namen gebauten Sufiwinkel und den dort anwesenden Derwischen gewisse Befreiungen zu und ermöglichte sogar, dass die Derwische ihre eigenen Scheichs wählen konnten, andererseits erlaubte sie aber die Ausübung gewisser Rituale nicht, die von der sunnitischen Wahrnehmung nicht akzeptiert waren und äußerte ihren Willen darüber, diese Rituale zu verbieten. Wenn dies auch paradox erscheint, so kann man sagen, dass dies dem elementaren Verhaltensmuster der osmanischen Zentralregierung in ähnlichen Fällen entsprach.

Wir werden in unserer kleinen Arbeit versuchen, einen Blickwinkel über den Stellenwert des Sufiwinkels in der osmanischen Welt zu eröffnen und den Sufiwinkel mit ähnlichen Mustern zu vergleichen, indem wir Dokumente und Quellen berücksichtigen, die diese beiden Wahrnehmungen zum Ausdruck bringen.

Schlüsselbegriffe: Seyyid Gazi, Seyyid Gazi Sufiwinkel, Sufiwinkel, Yunus Emre, Ritual 


\section{Seyyid Gāzi/Seydi Gāzi: İsim Meselesi:}

Bahsimiz olan aziz kişi aslında şecere olarak Hz. Ali soyu ile ilişkili değildir. O, aslında VIII. Yüzyılda Bizans’a karşı mücadele eden ve Türkler arasında görmüş olduğu sevgi ve ilgiden mülhem veli seviyesinde kabul edilmiş bir Emevi emiridir. ${ }^{1}$ Takriben 740 civarında bugün türbesinin bulunduğu yerde ölmüş ve I. Giyaseddin Keyhüsrev'in hanımının isteği üzerine bu mahalle türbe ve mescid inşa edilmiştir. Bu azizin bugün çoklukla kaydedilen ismi Seyyid Battal Gāzi'dir. Mühimme defterlerinde

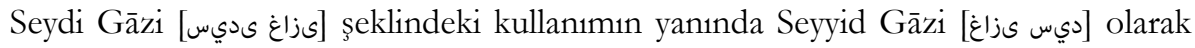
kullanımı da görülür. Ancak ifade ettiğimiz gibi Battal Gāzi, muhtemelen seyyid olmayıp zamanla veli seviyesinde algılanmış olduğu için ismi de bir seyyid nisbesi ile Hz. Ali geleneğine bağlanmıştır. Meşâirü’ş-Şuarâ yazarı Nikābi hakında bilgi verdiği kısımda bu manada bir bilgi nakleder. Belki mevzuyu anlatmak anlamında önemlidir: "kendüye aleviliğla uluv-ı himmeti var idi. Ol sebebden halk içinde siyâdet ile töhmeti var idı" (Âş1k Çelebi, 2010: 889) Türkler, kahramanlıktan mülhem O’nu Battal Gāzi olarak isimlendirmeyi tercih etmişlerdir. 1932 senesinde kaleme aldığı Rafizilik ve Bektaşilik adlı çalışmasında Ahmet Refik kullandığı belgeleri Seydi Gāzi şeklinde okumuştur. ${ }^{2}$

Seyyid Gāzi Zâviyesi bugün Eskişehir'de aynı ismi taşıyan ilçede hemen bütün ilçeye nâzır bir tepede bulunmaktadır. Adına tesis edilmiş olduğu Seyyid Battal Gāzi’nin kimliğini menkıbevi kişiliğgi içerisinden az çok ayıklayabilmek mümkündür. Bu çalışmanın konusu Battal Gāzi’nin kimliği olmadığı için konu bütünlüğü açısından sadece birkaç yönüyle vurgulanıp geçilecektir.

Menkıbeler içerisinden tarihselleştirilebilen yönüyle Battal Gāzi’nin Emevilerin Bizans'a yönelik gaza faaliyetleri içerisinde yer aldığı ve kaynaklara yansıyan şöhretini bu süreçte kazandığı anlaşılmaktadır. ${ }^{4}$ Menkabevi hayatını anlatan Battal-name, O'nun Malatya civarında yaşadığını anlatıyor olmakla beraber, Ahmet Yaşar Ocak bu yaklaşımın doğru olmadığını kaynakların naklettiği bilgilerden hareketle Kayseri,

1 Ahmet Yaşar Ocak, "Battal Gazi”, TDV. IA, V, 204.

2 Ahmet Refik, On altmnc Asirda Rafizilike ve Bektassilik, İstanbul 1932, s. 32.

3 Zâviye hakkında geniş bir monaografi olarak bkz. Theodor Menzel, "Das Bektaschi Klöster Sejjid Gazi”, Mitteilungen des Seminars für Orientalische Sprachen, 28(1925), ss. 92-125; Filiz Yenişehirlioğlu, "The Tekke of Seyyid Battal Gazi”, Anadolu ve Cevresinde Ortaçağ, sd. Mine Kadiroğlu, Ankara 2008, ss. 121-164; Suraiya Faroqhi, "Seyyid Gazi Revisited: The Foundation as Seen Through Sixteenth and Seventeenth-Century Documents", Turcica, Revue D'Etudes Turques, Tome XIII (1981), Paris, ss. 90-122.

4 Ahmet Yaşar Ocak, a.g.m., s. 204. 
Afyon, Eskişehir, el-Cezire ve Suriye bölgelerinde faaliyet gösterdiğine işaret etmektedir. $^{5}$

Seyyid Gāzi Zâviyesi’nin Anadolu Kalenderiliğinin en önemli merkezi olduğu muhakkaktır. Zâviye bu özelliğini hiç değilse XV. Yüzyılın ilk çeyreğinden XVII. Yüzyıla kadar devam ettirmiştir. Anlaşıldığı kadarıyla bu dönemlerden sonra Zâviye, hemen bütün Bektaşi kesimlerin ilgilerine mazhar olmuştur. Öte taraftan ifade etmek gerekir ki Battal Gāzi Zâviyesi, aynı zamanda kahramanlık ve gaza kültürünün önemli unsurlarından bir tanesini oluşturuyor olması sebebiyle, özellikle mağlubiyetler çağında toplumun hemen her kesiminin ilgisini çeken merkezlerden birisi olmuştur. Bu itibarla zâviyeyi sadece Kalenderi-Bektaşi unsurların hürmet ettiği bir merkez olarak mütalaa etmek mümkün değildir. ${ }^{6}$

Aşağıda ifade edileceği ve yazının da ana çerçevesini oluşturacağı gibi, gayrı sünni oluşumlarla arasına mesafe koymak konusunda son derece keskin çizgileri bulunan Osmanlı merkez yönetimi, Seyyid Gāzi ve elbette bunun gibi diğer bazı aziz kişiler ve onlar adına inşa edilen müesseseler bahis konusu olduğu zaman, bu mekânları ötekileştirmeden, son derecede dikkatli bir dil kullanmayı tercih etmiştir. Elbette bu özenli dili bazı müelliflerin yazdıklarında görebilmek mümkün değildir.

Tarihsel bilgi olarak yanlış olmasına rağmen günümüzde "Alevi” olarak adlandırılan, Osmanlı sufi geleneğinin bir veçhesi olarak ifade edilebilecek sosyolojik muhitin önemli temsil makamlarından birisi olan Seyyid Gāzi Zâviyesi'nin nüvesi, XIII. Yüzyılda Anadolu Selçukluları döneminde oluşturulmuş, türbe ve etrafında gelişen zâviye, bugünkü halini ise daha ziyade XVI. yüzyılda almıştır. Kanuni döneminde yapılan tahrirde Zâviyede iki yüz dervişin bulunduğu ifade edilmektedir. "Zâviye-i mezbûreye kayd olan büddâmından ve müteferrika dervişlerinden bil-fiil iki yüz nefer dervisler vardir'. (BOA. MAD 27: 52)

Zâviye, Anadolu'da dolaşan birçok yabancı seyyahın da dikkatinden kaçmamıştır. 1438 senesinde Türklere esir düşen ve yaklaşık yirmi sene Türkler arasında yaşamış olan Macaristanlı Georgius Türkler üzerine kaleme aldığı eserinde bu zâviyeye değinir. Kendisi Seyyid Gāzi'den bahseden en erken tarihli gezginlerden birisi olarak kabul edilebilir. ${ }^{7}$

5 Ahmet Yaşar Ocak, a.g.m., s. 204.

6 Fuat Köprülü bu anlamda Seyyid Gazi'ye ithaf olunan mezarın o civarda pek muhterem olarak kabul edildiğini belirtir. Bkz. Türk Edebiyatında İlk, Mutasavviflar, Ankara 1984, s. 233.

7 Ahmet Yaşar Ocak XVI. ve XVII. Yüzyıl batılı gözlemcilerinin eserlerinde nakledilen bilgileri eserinde değerlendirmiştir. Ahmet Yaşar Ocak, Osmanl Imparatorluğunda Marjinal Sufilik: Kalenderiler (XIV-XVII. Yüryyllar) Ankara 1992, s. 176 vd. 
Georgius'un gözlemlerine göre Seyyid Gāzi, Kalenderiler nezdinde kutsal kabul edilmektedir. Georgius, burayı kutsal kabul eden Kalenderilerin kulaklarına mengüş/ küpe taktıklarını, bendir çaldıklarını da belirtir. ${ }^{8}$ Burada yapılan yıllık merasimlere de değinen gezgin yapılan törenlerin "Mahya" olarak adlandırıldığını da ifade eder. Tespitlerime nazaran merasimleri bu isimle adlandiran ilk kaynak da bu eserdir.

$\mathrm{Bu}$ yıllık merasimler yine aynı isimle yani "Mahiye" olarak klasik dönem Osmanlı belgelerinde de yer almaktadır.' Seyyid Gāzi Zâviyesi, anlaşıldığı kadarıyla Kalenderiler dışında sair Müslümanların da itibar ettikleri bir kutsal mahal olarak kabul edilmektedir. Zira Georgius, Türklerin özellikle savaş ve kıtlık zamanlarında ve çarpışmalarda Seyyid Gāzi'ye dua edip de isteği geri çevrilen kimse olmadığına inandıklarını, ${ }^{10}$ bu inanışlarını sultanın, yöneticilerin ve halkın her sene türbeye sundukları çeşitli adaklar ve hediyeler ile desteklendiğini ifade etmektedir. Hatta Seyyid Gāzi’nin ününün Türklerden başka diğer Müslüman unsurlar arasında da yayılmış olduğuna işaret edilmektedir. ${ }^{11}$

Zâviye, muhtemelen XVI. yüzyıla kadar Kalenderiliğin merkezi olma özelliğini devam ettirmiş fakat yüzyılın sonlarına doğru Mühimme defterlerinde yer alan bir kayıttan anlaşıldığı kadarıyla Seyyid Gāzi kasabası ahalileri "ulemâ ve sulehâ ve sâir eşrâf ve a'yânı" İstanbul'a bir mektup göndererek "Mahiye" merasimlerinden duydukları rahatsızlığı ifade etmişler ve devlet bunun üzerine aşağıda Âş1k Çelebi'nin eserinden naklen metni aktarılacağı üzere zâviyede bir teftiş yürüterek bu merasimlerin yasaklanmasına ve zâviyenin cami ve medrese olarak faaliyetlerine devam etmesine karar vermiştir. $\mathrm{Bu}$ tarihlerden sonra süregelen merasimlerin tamamen kesilip kesilmediği konusunda bilgimiz bulunmuyor. Ancak her halükârda zâviyenin geleneksel yapısında köklü bir değişikliğin bu tarihlerden sonra geliştiği muhakkaktır.

Ahmed Refik'in kaydettiği 15 Safer 980 (M. 27. VI. 1572) tarihli Divân-1 Hümâyun kaydında yıllık merasimlerin yeniden ihya edilmeye çalışıldığı görülüyor. "cami ve mezar-l serifin hareminde tablhane ibdâs edüb ynlda bir kere mabiye dedikleri bid'atlerin yine peyda 8 Altay Tayfun Özcan, "Macaristanlı Georgius'a Göre XV. Yüzyll Türkiyesindeki Heteredoks

Kesim”, Diyalog, Interkulturelle Zeitschrift für Germanistik, 2 (2013) s. 114; Zeynep Yürekli, Legend and Architecture in Ottoman Empire: The Shrine of Seyyid Gazi and Hace Bektass (PhD diss., Harvard University), 2005; Zeynep Yürekli, Arbitectureand Hagiography in the Ottoman Empire, The Politics of Bektashi Shrinesin the Clasical Age, New York 2012, s. 5.

9 “Seydi Gāzi Mahiyesi” BOA. MD. 73, s. 302/881.

10 Macaristanlı György, Türkler, Türklerin Gelenekleri, Görenekleri ve Hinlikleri Üz̧erine İnceleme, Michel Balivet, Türk Korkusu, çev. Lale Arslan Özcan, İstanbul 2009, s. 92.

11 Macaristanlı György, Türkler..,s. 93. 
edüb etraftan nice feseka cem' olub harem-i mezburda tabl ve nakkare ve șişte ve kopuz çalinub mal-ı vakıı bî müfîd yerlere sarf olunmak üzeredir" Muhtemelen bu süreç böylece devam etmiş ve yüzyılın sonlarına doğru devlet bu merasimleri yeniden yasaklama gereği duymuştur. (Ahmet Refik, 1932: 32-33)

\section{Seydi Gā̃i kadısına büküm ki;}

Südde-i saadetime mektûb gönderüb kasaba-i mękêurenin ulemâ ve sulehâ ve sâir eşrâf ve a'yâm șer'-i șerîfe gelüb beher senede Seydi Gāzi mâbiyesi nâmma güz eyyâminda aẑ̧̀m cem'iyet olub yeniçeri ve acemi oğlam ve onlar nâmına nice ehl-i fesâd cem' olub müslimînimn ehl-i a'yâlleri üzerine konub nice fesâd ve șenâ'at olduğundan gayr câmi-i şerîf hareminde sâzendeler cem' olub sąlar çalub hengâm etmekle namaz kılmak mümkün olmayub men' olunmak murâd olundukta kadimden oligelmişdir deyu memnu' olmayub ve tüccardan bey ü şirâ edüb evine giden müslimînin yollarna inüb mal ve menâlleri gâret ve kendilerin katl edüb aẑ̧̀m mefsede olmağm min ba'd cem'iyet-i mezbûre men ve def' olunmak ricâ eylediklerin arz eylediğin ecilden buyurdum ki vardukta arz, olunduğu üzere fesâd ve [...] bâis olub mâhiye nâmma olan cem'iyeti men edüb min ba'd şer'-i şerife mugâyir kimesneye is ettirmeyesin ve bu emr-i serifime mubalefet edenleri yazub ar: eyleyesin (BOA. MD. 73: 302/681)

Kayıtta da dikkat çekeceği üzere Osmanlı merkezi yönetimi zâviyede toplanan kalabalığı hiç azımsamaz ve onlardan "az̧im cem'iyet' olarak bahseder. Kanun koyucu, toplanan kalabalığın iki yönünden bahseder. Birincisi kalabalığın, civarda genel olarak bir asayişsizliğe sebep olduklarının vurgulanmasıdır. Bu asayişsizlik içerisinde yol kesmek, hırsızlık, katl gibi vakalardan "nice fesad ve şenaat" olarak tanımlanan çeşitli suçlara kadar birçok unsura dikkat çekilmiştir. İkincisi ise bizi daha ziyada ilgilendiren yönü ile “câmi-i şerîf hareminde sâzendeler cem' olub saz̧lar çalub hengâm etmekle namaz. kulmak mümkün olmayub" ifadeleriyle tanımlanan, kalabalığın caminin içerisine girerek orada bir ayin icra ediyor olmaları gerçeğidir.

XIII-XIV. yüzyıllarda İslam dünyasında mevcut dervişlerin önemli şiarlarından birisinin seyahat/gezginlik olduğu bilinmektedir. Belki "Seyahat ediniz çünkü akan su temiz olur" düsturu, ancak daha ziyade geçim temini için uzak mesafeler arasında bile seyahat eden derviş gruplar için, Osmanlı dünyasının muhtelif yerlerinde çok sayıda dervişin iştirakiyle gerçekleşen merasimler dikkat çeker. Kalenderiler konusunun en yetkin monografisinde Ahmet Yaşar Ocak, Seyyid Gazi'de yapılan bu merasimin Kurban bayramında icra edildiğini ifade eder. (Ocak, 1992: 176) Yağmur Say aynı bilgiyi tekrarlayarak bu merasime Hacılar bayramı da denildiğini ifade eder. (Say, ty: 
146) Konu hakkında hemen hemen en son çalışmayı kaleme alan Resul Ay da mevcut literatürü kapsamlı bir şekilde nazarı itibara aldığı makalesinde bu merasimlerden bir tanesinin Seyyid Gāzi'de ve Kurban bayramına tekabül eden günlerde yapılageldiğini, benzer bir merasimin de 10 Muharremde Hacı Bektaş Dergâhı'nda icra edildiğini belirtir. (Ay, 2015: 307) Ancak belgeler, Mahya olarak adlandirılan bu merasimin Kurban Bayramı'nda yapıldığına dair bilgi sunmaz. Elbette bu merasim esnasında çok sayıda kurbanların kesilmekte olduğu yadsınmaz bir gerçektir. Her halükârda bu merasimin Kurban bayramı ile bir alakasının olmadı̆̆ı muhakkaktır. Osmanlı belgeleri merasimin "güz eyyamı" olarak sabit bir dönemde yapıldığını ortaya koyar.

Günümüzde Eylül ayının başında Seyyid Gāzi'de şenlikler yapılmaktadır. Anlaşıldığı kadarıyla bu anma şenlikleri ile mıntıkada yapılan kadim mahya ayininin bir irtibatı olmalıdır. Hattı zatında "güz eyyamı" olarak bahsedilen mevsim, sonbahar ayları olup Eylül-Ekim ve Kasım ayları yani kış hazırlığının başladığı dönem olarak kabul edilmektedir. Bu ayin ya da merasim bir anlamda ürünlerin toplanmasinin ardından bir nevi şükür ve kışa hazırlık olarak mütalaa edilebilir.

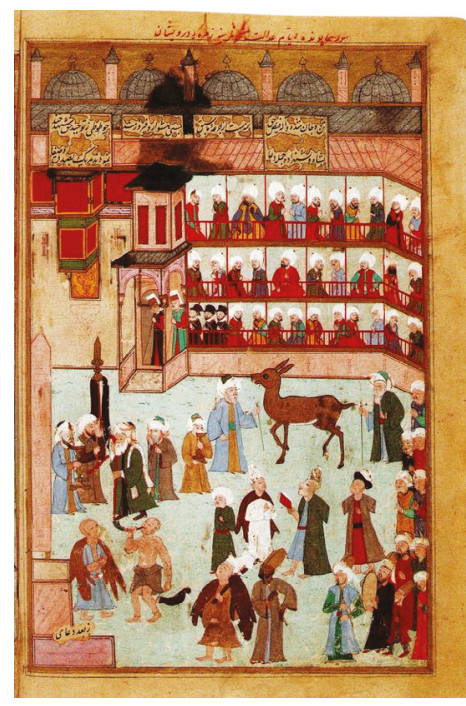

$\mathrm{Bu}$ tarihlendirme konusunda yukarıda verdiğimiz mühimme kaydının tarihi belki açıklayıcı olabilir. Şöyle ki kasabanın eşrafının yapılan bir mahyanın ardından şikâyet anlamında bir yazı yazması mantıklı görünüyor. Mühimme kaydının tarihi biraz sorunlu olarak dikkat çekiyor. Zira hükümden önce verilen son tarih Gurre-i Z 1003 (M. 7. VIII. 1595) tarihidir. Ĕger bu tarihi kabul edersek, ahalinin merasimlerden yaklaşık bir ay kadar önce Ağustos ayında konuyu İstanbul'un bilgisine sunduğu kabul edilecektir. (BOA. MD. 73: 294) Ancak bu sayfa ile yukarıya aldığımız hüküm (BOA. MD. 73: 302/681) birbirini takip eden hükümler olmayabilir. Zira Seyyid Gāzi kadısına yazılan bu hükmün hemen altında yer alan (BOA. MD. 73: 302/682) numaralı hükmün ulağa verilme tarihi 29. Za 999'dur. (M. 18. IX.1591) Dolayısıyla bir üstte yer alan Seyyid Gāzi konulu hükmün de bu tarihler civarında yani eylül ayının başlarında kaleme alınmış olması düşünülebilir. 
İçerik olarak bu merasimlerin inanç grubunun geleneğinde bir karşıllı̆ının olup olmadığ1 ya da belli araştırmalarda "hacılar bayramı" olarak yapılan tanımlamalar örneğinde olduğu gibi inanca ait bir yönünün olup olmadığını söylemek zordur. ${ }^{12}$ Ancak, Selçuklular çağından beri süregelen bir gelenek olduğu muhakkaktır.

Anlaşıldığı kadarıyla bu ayin esnasında sazendeler vardır ve sazlar çalınmaktadır. O halde burada şu soruyu sormakta fayda var. XVI. yüzyılın belgelerinde anlamını bulan bu sazendelerin çaldıkları sazlar nelerdir? Bugün Alevi semahında saz dişında kullanılan bir musiki aleti genellikle görülmez. Ancak metinde ifadesini bulan "sazendeler" tabiri, sanki içerisinde başka sazların da barındığı intibaını vermektedir. Zira Hacı Bektaş dergâhında müzede kırklar meydanında muhafaza edilen bir şamdanın kaidesinde semah yapanlarla beraber kudüm ve tambur gibi müzik aletlerini çalanların resmedilmiş olduğu ifade edilmektedir. (Elçi, 1999: 14) Ahmet Refik'in kaydettiği divan-1 hümayun kayıtlarından birisi bu manada son derecede önemlidir. Zira burada merasimin yasaklanmasindan sonra yeniden ihdas edilmesi sürecinde türbe hareminde toplanan ziyaretçilerin tabl ve nakkare ve sistse ve kopuz çalmakta oldukları kaydedilmiştir. Burada ifadesini bulan şişte bildiğimiz tamburun öncüsü olan şeştâr veya daha küçük bir halk çalgısı olan çeşde olmalıdır.

Ayinlerin yeniden başladığından bahseden ve Ahmet Refik tarafından neşredilen Divan-1 Hümayun kaydındaki "yoluk ve çılak yürümemek üzere" şeklinde kaydedilen bir tanımlama, merasime katılanların niteliğini de ortaya koymaktadır. Belge, vaktiyle yasaklanan merasimlerden bahsederken bu türlü hareketleri olanların ve "csplak ve rafz ve ilhad üzere olan ışıkların aralarna.." karıştırılmaması şartı ile zâviyenin ihyasına izin verildiğinden bahisle "bed mez̧heb üzere içlerinde asla bir ferd»" barındırmamaları ve beş vakit namazı terk etmemeleri şartına dikkat çekmektedir. $\mathrm{Bu}$ anlamda vaktiyle burada merasim yapanları bî- namaz oldukları da ifade edilmektedir. "evkat-ı hamsede müdâvemet etmeyüb bî namaz olanlarn sen ki toprak kadısısin daima tetebbu edip...." Bütün bunlar, daha XVI. yüzyılın sonlarına doğru etrafta Kalenderi zümrelere mensup dervişlerin bulunduğunu göstermesi açısından önem taşımaktadır.

12 Alevi Bektașilerde tertiplenen bu kabil merasimlerden bazıları hakkında bkz. İrene Melikof, Anadolu Alevilerinin Bazı Törenleri Üzerine”, Yabancı Arastırmacllar Göz̈ülle Alevilik-Tuttum Aynayı Yǚüme Ali Göründü Gözüme, çev. İlhan Cem Erseven, İstanbul 1997, ss. 61-64; İrene Melikof, "Alevi Adetleri Üzerine Notlar, Bazı Orta-Anadolu Kutlamaları Dolayısıyla”, İrene Melikof, Uyur İdik Uyardilar, Alevilik Bektassilik. Arasstormalar, trc. Turan Alptekin, İstanbul 1993, ss. 81-87. 
Mahya ayinine sayısı binlerle ifade edilebilecek insan katılmaktadır. Anlaşıldığı

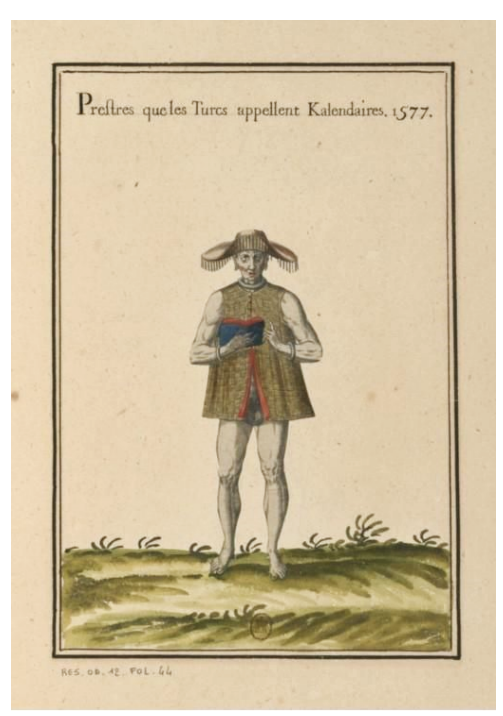
kadariyla afyon da kullanılan merasimler sırasında kendisinden geçen dervişler, çok bilinen, kalenderi dervişin biçakla kendisini yaraladığ1 gravürde görüldüğü gibi vücutlarının belli yerlerini kesmekte ve bir ateşin etrafinda çalınan ezgiler eşliğinde sema/semah denilen ayini icra etmekteydiler. (Ocak, 1992: 176-177)

Anlaşıldığ1 kadarıyla Kalenderiler ve abdalların yillik olarak muhtelif yerlerde yaptıkları ayinler bu isimle anılmaktayd1. Zira Otman Baba Vilâyet-nâmesi'nde Zağra'da Mal Öyüğü denilen köyde, mahya olarak adlandırılan merasim kapsamında bir cemiyet gerçekleştirildiği nakledilmektedir. İfadeden anlaşıldığ1 kadarıyla bu merasim için de tıpk1 Seyyid Gāzi gibi muhtemelen imparatorluğun mümkün olan her coğrafyasından insanlar toplanmaktayd1. (Gölpınarl1, 1995: XCVI-XCVII) “...meğer Zağra'da Mal Öyügü dirler bir kö̈de bir gürub sufiler mabya etmek kasdina her diyardan balk u dervisleri da'vet itdiler ol kân-ı vilâyet tekyesinde dervişi dabi ol mabyaya da'vet edüb tenbih itdikede ol kân-ı vilâyeti anda gördiler ve âlem halkına meşhur ve haber edüb aytdılar kim ol server-i âlem ve maksûd-ı âdem kim Otman Baba'dur filan dervişin tekyesinde buzur-ı vahdet eyler dediler çün ol abdallar dahi ișitti kim ol kân-ı vilayet filan yerde mabyaya gelse gerekdür pes ol mabyaya ažm-i dil-ârâm etdiler ve ol Mal Öyügü didükeleri mabya olacak köye geldiler; gördiler ki ni’met pişmiş ve hak ü dervis cem' olmağa başlamıs öyle olsa bir yire oturub intizar ve ümid birle yol gözetdiler ki bir lahzadan sonra gördiler ki ol tekyesinde olduğu dervişin ardinca ol kân-ı vilayet çoban-vari bir uğucu mübarek, çulunu geçirüb omuzuna urmıs, gelür ve bir tac dikinmis, yedi terk üzerine ve mübarek başınun saçı ol tac altında bir tutam mikdâr uzamış" Bu şenliklerin bugün Balkanlarda bazı yerlerde küçük çapta yapılageldiği bilinmektedir. Tire Dibekçiler yaylası/Çaldede mahyası, Köyceğiz Sandıraz dağı mahya şenlikleri (Önal, 2003: 104) örneğinde olduğu gibi Anadolu'da da devam etmektedir.

Güz eyyamında büyük bir kalabalığın toplanması ile gerçekleşen bu ayin/ merasimler nasıl icrâ ediliyordu? İçeriğinde neler vardı? Bu sorulara belki bugünden geriye giderek cevap vermek mümkün olabilir. Ancak asıl kaynak hiç şüphesiz 
Georgius'un eseri olarak ifade edilebilir. Konu hakkında elimizdeki en erken veriler de burada yer almaktadır. Buna göre dervişler kapalı bir mekânda toplanmakta ve hayvanlar kurban etmektedirler. Yine buraya gelirken yanlarında yiyecekler de getirdikleri anlaşılmaktadır. ${ }^{13}$ Toplanılan yerin dolmasının ardından muhtemelen zâkir olarak tanımlanan kişi eline bir bendir alarak semah yapmak üzere ayağa kalkan kişileri, belli ritimler dairesinde hareketlendirmektedir. Semah dönenlerin belli bir insicam dairesinde döndükleri Georgius'un ifadelerinde yer alan, hiç kimsenin bu dönenleri insan $\mathrm{m}$ heykel mi ayırt edemez ifadelerinden anlaşılmaktadır. ${ }^{14}$ İcra edilen ayinin ritminin yavaş yavaş yükseldiği ve bu esnada Yunus ilahilerinin okunmakta olduğu da ifade edilmektedir.

Daha XV. yüzyllın ortalarında Seyyid Gāzi Zâviyesi'nin henüz Kalenderiliğin önemli merkezlerinden olduğu tarihlerde, buradaki ayinlerde Yunus Emre'nin ilahilerinin okunuyor olması son derecede önemlidir. Zira Yunus'un Sünni dünyanın $\mathrm{m} 1$ yoksa Sünni dışı dünyanın $\mathrm{m} 1$ bir ürünü olduğu tartısması el-an devam edegelmektedir. Merasimlerde ilahilerinin okunuyor olması Yunus Emre gibi yüzyıllar boyunca çok geniş bir coğrafyada çok farklı kesimlerin üzerinde etkin olmuş bir kimseyi Sünni dünyanın dışına elbette taşımaz. Ancak Yunus'un ilahilerinin Seyyid Gāzi Zâviyesi'nde okunuyor olması O'nun bu muhitlerde de etkin olduğunu göstermek açısından önem taşımaktadır. ${ }^{15} \mathrm{Bu}$ merasimler sırasında Yunus Emre'den okunan ilahiler Georgius tarafindan kitabına dâhil edilmiştir. Latince söyleyiş ile kaleme alınan ilahilerin karşılıkları Leyla Coşan tarafindan tespit edilmiştir (Coşan, 2009: 205)

Caffil olma aths goesingi. halinga bak Gâfil olma aç gözüni hâluna bak öleni oeleni goer. Ruenelit itma doennede. gör Kürelik itme dünyede yazuklarun yasuclerungdeleni goer dileni gör

13 Georgius'u Latince aslından incelediğini ifade eden Altay Tayfun Özcan, bu yiyeceklerin merasim sürecinde yenilip içildiğinden bahsedilmemesinin bunların ihtiyaç sahiplerine dağıtılmış olması ile izah edilebileceğini ifade etmektedir. Ancak çok uzak diyarlardan gelen binlerce dervişin toplandığı bir yerde getirilen yiyeceklerin önemli bir kısmının tüketilmiş olması daha mantıklı görünüyor. Bkz. Altay Tayfun Özcan, a.g.m., s. 115.

14 Altay Tayfun Özcan, a.g.m., s. 115.

15 Yunus Emre'nin Alevi Geleneğindeki yeri için bkz. Mehmet Ersal-Bülent Akın, "Alevi Geleneğinde Yaşayan Yunus Emre”, Uluslararası Yunus Emre Semposyumu Bildirileri, Edt. Ünal Şenel, Manisa 2016, ss. 163-199. 
Nitstheler yatir duessuebeni. gir nulan tstheyan uessuebeni

Czuemuekleri tsassabeni. tsthuerrybeni olam guer.

Kym Ach iduep kilir zari. kuenethdur ellinde uuari.

Gutsthmisth yatir kari giri. myzkynueri guueleni goer

Czorma hallynkymczene. uuarma yeramanczine Kymczini goefdeczini uulsb gyeni iulani goer.

Hane mehenimet mustafa. huekym itti kaftan kafa Doenne kyme kildi baffa. aldaniben galani goer.

Aldanma mala dauuara kuluk eyla haka yar Seuigile bile uuara. baki iotasth olani goer.

Jonus bii czusleri tsattar. halka morifet satar Gendiczi ne hadar duttar czoledigi ialani goer.

Janar itschim goner osim bon oelim angitstac

Olim endestherczin hosth. ululara damtsthag

Oliczeris belli bean. gisli itsthimis olor ean.

Tenesthir ustine konp. halk vnginde iuumtsthad. Hitsch hilmeczem ben nitge idem. hanke ianna czaffaridem

Yaccaffis don geem gidem. baschsis atta binnitstheg.
Niçe yatur düşübeni 1lan çıyan üşübeni Sünükleri çagşabanı çüriyüben ulanı gör

Kimi âh idüp k1lur zârı günehdür elinde varı Göçmiş yatur kara yiri miskinleri güleni gör

Sorma hâlın kimisine varma Irahman 'suzına Kim isine gövdesine ulşup yeni yeni yolanı gör

Kanı Muhammed Mustafâ hüküm itdi Kaf'dan Kaf'a

Dünye kime kıldı vefâ aldanuban kalanı gör

Aldanma mâla davara kulluk eyle Hakk'a yara Seviyile bile vara bâkî yoldaş olanı gör

Yûnus bu sözleri çatar halka ma'ârifet satar Kendüsi ne kadar dutar söyledügi yalanı gör

Yanar içüm göyner özüm ben ölü (mi) anıcak Ölüm endişesi ne hoş ululara danı(şa)cak

Öliserüz bellü beyân gizlü içümüz olur '1yân

Teneşür üstine kon(up) halk öninde yuvunicak

Hiç bilmezem ben niçe idem kangı yana sefer idem

Yakasuz don geyem gidem başsuz ata bini(şi)cek 


\begin{tabular}{|c|c|}
\hline $\begin{array}{l}\text { Gele banga kauum gardasth ola } \\
\text { czimdegi ioltasth. }\end{array}$ & $\begin{array}{l}\text { Gele bana kavum kardaş ola si(ne) } \\
\text { degi(n) yoldaş }\end{array}$ \\
\hline $\begin{array}{l}\text { Kim olaczar banga haltasth. ben } \\
\text { zinindo egalitsthag. }\end{array}$ & $\begin{array}{l}\text { Kim olısar bana haldaş ben sinümde } \\
\text { kalı(şı)cak }\end{array}$ \\
\hline $\begin{array}{l}\text { Galam ben amalimla. hernitgeczii } \\
\text { alimla }\end{array}$ & $\begin{array}{l}\text { Kalam ben âmâlum(1)la her niçesi } \\
\text { hâlum(1)la }\end{array}$ \\
\hline $\begin{array}{l}\text { ide kauum guule guele. efden ianga } \\
\text { onitstheg. }\end{array}$ & $\begin{array}{l}\text { Gide kavum güle güle evden yana } \\
\text { döni(şi)cek }\end{array}$ \\
\hline $\begin{array}{l}\text { Sanga aidirem ai passa. nelergelliczor } \\
\text { bassa. Kiming izciden bagir pissche. } \\
\text { kim schraba kanitsthag. }\end{array}$ & $\begin{array}{l}\text { Sana eydürem ey paşa neler geliserdür } \\
\text { başa } \\
\text { Kimi isiden bagri pişe kim şarâba } \\
\text { kanı(şı)cak }\end{array}$ \\
\hline $\begin{array}{l}\text { Yarin cziaczat gurla tschumla galeik } \\
\text { derle. }\end{array}$ & $\begin{array}{l}\text { Yarın siyâset kur(1)la cümle halâyık dir(i) } \\
\text { le }\end{array}$ \\
\hline $\begin{array}{l}\text { Kime mir czeuun herle. kiming izciden } \\
\text { lamtsthag. Amal vuer vnda tsthoap } \\
\text { amalsisa olor hedep. }\end{array}$ & $\begin{array}{l}\text { Kim(i) emir sa(e)van birle kimi isiden } \\
\text { yan1(ş1)cak }\end{array}$ \\
\hline $\begin{array}{l}\text { Schol hisschia olmacz hezzep. bunda } \\
\text { azat olitsthag. }\end{array}$ & $\begin{array}{l}\text { Âmâl vir(e) anda cevâp âmâlsuza olur } \\
\text { itâb } \\
\text { Şol kişiye olmaz 'azâb bunda âzâd olı(şı) } \\
\text { cak }\end{array}$ \\
\hline $\begin{array}{l}\text { Yonus emdi kil iarak. vtanmeaczin } \\
\text { dogri bak. } \\
\text { Tscumla galeik derle. Atli atila } \\
\text { czaiilitschag. }\end{array}$ & $\begin{array}{l}\text { Yûnus imdi sen k1l yarak } \\
\text { utanmayasın dogrı bak Cümle halâyık } \\
\text { dir(i)le adlu adı(y)la sayılacak }\end{array}$ \\
\hline
\end{tabular}

Anlaşıldığı kadarıyla Seyyid Gāzi Zâviyesi İşreti'nin kapsamlı teftişinin ardından devletin "Işık" tabir ettiği unsurlardan arındırılmıştır. Bu Işıkların kalenderi zümreler olduğu ifade edilebilir. 15 S 980 (M. 27.VI.1572) tarihli mühimme kaydında "ol makamdan mukaddemâ reddolunan Işık taifesi” ifadesi ile bu döneme işaret edilmektedir. Mühimme kaydında "evvelki fiska müteallı adetlerin terk edüb ebl-i sünnet ve cemaatten olup evkat-ı hamseye müdavemet edüb yoluk ve çplak yürümemek üzere" ifadeleri bu zümrenin Kalenderi unsurlar olduğunu çağrıştırmaktadır. (Ahmet Refik, 1932: 32) Georgius'un tanımladığı Kalenderi gruplar da Osmanlı belgelerinde tarif edilenden çok farklı 
değildir. O’na göre bu dervişlerden bazıları başlarında tüyler taşır, yamalı kıyafetler giyinirdi. Ancak çoğunluğu çıplak denilebilecek şekilde ve yanlarında zincirler bulunduğu halde idiler. Buna rağmen onlar halk ile tamamen uzak kesimler değillerdi. İçlerinden sadece bir kısmı toplumdan ayrılarak dağlara çekilmekte idi. (Özcan, 2013: 114)

Öte taraftan, Âşık Çelebi'nin İşreti hakkında naklettiği bilgiler arasında çizdiği Seyyid Gāzi Zâviyesi portresi içerisinde kullandı̆̆1 “bizüum namą̦ımı kılınmış kefenimiz. dikilmiştir’ ifadelerini, Osmanlı belgelerinde rafizi olarak tanımlanan ve muhtemelen nadiren XVIII. yüzyıldan itibaren, ancak genellikle XIX. yüzyılda Alevi olarak isimlendirilmiş olan zümreler için ifade edilen isnad ve suçlamalardan birisi olduğunu da belirtmek gerekir. ${ }^{16}$

Mühimme kaydının bizlere ifade ettiği bir diğer konu, Seyyid Gāzi kasabası ahalilerinin top yekün olarak aynı inanç grubunun mensupları olmadığı gerçeğidir. Zira belgede ifadesini bulan zümreler "ulemâ ve sulehâ ve sâir eşrâf ve a'yâni" içerisinden ulemanın kamu otoritesinin temsilcileri, dolayısıyla dişarıdan olan unsurlardan olduğu kabul edilse bile diğerlerinin kasabanın mensupları olduğu muhakkaktır. Ĕger Osmanlı merkez yönetiminin yapılacak işlemi meşrulaştırmak için böylesi bir sebep zikretmiş olabileceği ihtimalini kenarda tutarsak, çevrenin de bu merasimlerden rahatsız olduğu ifade edilebilir. Bu bağlamda metinde ifadesini bulan, cami içerisinde namaz kılmanın mümkün olmadığı iddiası hem kasaba ahalilerinden bazılarının bakışını hem de devletin zâviye hakkında yapılacak bir işlem için nazarı itibara aldığı gerekçeyi göstermesi açısından önemlidir.

Dikkat edilecek olursa Osmanlı merkez yönetimi müessesenin yüzyıllardan beri süre gelen etkinliğini iptal ederken, kurumu hiçbir şekilde hedef almaz. Kurum çerçevesinde yapılan uygulamalar bu müdahalenin sebebi olarak ifade edilir. Hatta Seyyid Gāzi'de olduğu gibi vakıf malına müdahale, su-i istimal konusu çok zaman bu mesele içerisinde bir gerekçe olarak ifade edilir. Osmanlı yönetimi, vakıf muhasebesi bile olsa, defterin ser levhasinda bu kabil sufiler hakkında fevkalade tazimkâr bir ifadeyi formüle etmiştir. Velev Osmanlı yönetiminin takibatına uğramış zümrelerin piri olarak kabul edilse bile.

Bunun ilginç örneklerinden bir tanesi yine Seyyid Gāzi İmareti hakkında Kanuni döneminde tanzim edilmiş olan bir defterde yer alan kayıtlardır. Bu kayıtlar,

16 BOA. $M D$. nr. 69 , s. 59/115: 
zâviyenin işleyişinden kaynaklanan bazı meselelerin devlet tarafindan nasıl karara bağlandığını göstermesi açısından son derecede önemlidir. Mesela şeyh olan kişilerin vakıf mahsulü ile toplanan nezirlerin öşrünü meşihatları gereği almalarına müsaade edilmiştir. Ancak, zâviyede vefat eden dervişlerin ve kulların terekelerinin öşrüne de müdahale etmek istediklerinde bu gelirden men edildikleri dikkat çeker. (BOA. MAD 27: 57) Hatta vârissiz ölenlerin zâviyede sarf edilecek olan mallarından resm-i kısmet talep eden kadıların bile müdahalelerini men ederek zâviye sarf edilecek gelire noksan gelmesinin de önüne geçilmiştir. Seyyid Gāzi dervişlerinin kendi gayretleri yaptıkları sekiz göz değirmenin gelirini imaret için sarf ettikleri, yirmi beş yıldan beri değirmenin böyle işlediği, şimdi şeyh olan kişinin tıpkı vakıf malından aldığı öşür gibi değirmen gelirinin de öşrünü almak istediği anlaşılmaktadır. Merkez yönetimi, bu meselenin de incelenerek değirmen vakıf malı değil ise şeyh olanların bu müdahalelerinin engellenmesini âmirdir. (BOA. MAD 27: 57) Belki bunlardan daha da önemlisi defterde sureti yer alan Evâsıt-1 Ramazan 937 (M. 18-28. IV. 1531) tarihli bir divan kaydında dervişlerin şeyh olmasını uygun gördükleri kişiyi İstanbul'a bildirmelerini istemektedir. "Zâviye-i mezbûrede cihet ile șeyh olmak ref' olunmasın emr eyleyüb buyurdurm ki bükm-i serifim vusul buldukta göresiz zâviye-i mez̧burede olan dervişlerin içlerinden kendü ibtiyarlaryla eyledükeleri bir [...] ve münasib derviş Hüseyini şeyh tayin eyleyüb bürmet-i meşihatini ana ısmarlayasın zâviye-i mezbureyi görüb göz̨edüb eda-i bizmet eyleye ve dervişler şeyh olmak içün her kimi ibtiyâr edüb vech-i münâsib görmüsller ise yazub dergâh-ı muallâya arz edesiz ki bâb-ı saadet-meâbımdan berât-ı bümâyûn verilüb bürmet-i meșihati müeddi kula söyle bilesin ve ba'de'n-nazar bu bükm dervişler elinde ibka edüb alâmet-i şerîfe i'timad kulasız. tabriren fi evâsit-ı şehr-i Ramazanül- mübârek sene seb'a ve selâsîn ve tis'amiye"(BOA. MAD. 27: 58-59) Bu kayıt, Osmanlı yönetiminin daha henüz teftişler başlamadan ve burada yapılan merasimlere kısıtlama getirilmeden önce zâviyeye bakışını, dervişlerin şeyhin tespitindeki rollerini göstermesi açısından son derecede önemlidir.

Osmanlı merkezi yönetiminin Seyyid Gāzi hakkında bu dikkatli tutumuna karşın sünni dünyanın temsilcileri olarak kabul edilebilecek bazı müelliflerin eserlerinde, Seyyid Gāzi muhitinin temsilcileri olan sosyal muhit ile beraber müessesenin de tezyifkâr ifadelerin muhatabı olması dikkat çekmektedir. Âşık Çelebi’ in tezkiresi bunlardan bir tanesi olarak ifade edilebilir. Kanuni zamanında bir kadı olarak Seyyid Gāzi Zâviyesi’ni denetleyen İşreti'nin biyografisinin anlatıldığı kısımda zâviyeyi "Anadolida Seydi Gäzi tekyesi ki bir dâr-ı fisk u dalâl olub" ifadesi ile betimleyen yazar 
İşreti'nin zamanında zâviyenin teftiş edildiğinden bahisle vakıf gelirlerine gadr ve hiyanetleri olduğunu da ilave etmekten geri durmaz. ${ }^{17}$

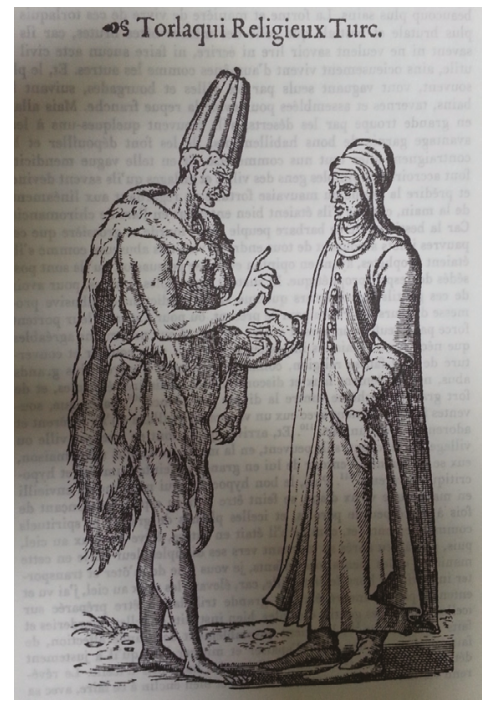

"Anadolida Seydi Gāąi tekyesi ki bir dâr-ı fisk u dalâl olub her yirden atasin anasin azarlatmıs battallar işden kaçub ışı olmus postun boklar abdallar sâz-ı melâhi gibi dem-sẫ çibreleri bilye-i imân olan libyeden âri ve almlarnda olan kara yazular ebrularmun terâssyla mütevâri idi. Namazumı kellnmış ve kefenümiz dikilmis ü ilinmişdür/alınmısdur diyü bi'külliye bis vakte çâr tekbîr idüb namaza yüz yumazlar ve müezzine kulak kabartmayn imâma uymazlar idi. Pâdişablarun sadakâtın ve ashâb-ı hasenâtun hayrâtın yirler birkaç gâv şikem-perver harlar idiler. Sultanöni, sancağma başka sancak çeküb etrafa akin salarlar tuğ ve nakekare ile beğler alaylarn görseler yuf borusun çalarlar idi. Kudümlarndan kûy u kent halker mütenebbib olsalar Deccal gibi ardlarna uyarlar buduklar dil-beri soyarlar kendü libaslarna koyarlardı. Dânişmed müderrisine incinse sipâhi ăgasina küsünse yalın yǖlüler babasına kakusa kandasın Seydi Gāzi Ocă̆ diyü varurlar, soymurlar kazan kaynadurlar. Işılar anlar semâ ü safa diyü kendi ezgilerine oynadurlar idi. Nice yul bu halle rüzgâr geçürüb dine vü müslimîne adü ve ilme vü ulemaya kîne-cü idiler. Ebl-i şer'e hod adâvet etmeyince zu'm-ı fâsidlerince hakla hak olmąlar ve ku₹âta istihfâf kulmasalar müfredliğa istibkak bulmazlardı. Hikmet Allab'un ve mu'cize Resula'llabundur sırr-ı 'ilm ve rûbâniyet-i ulemâ ve gayre-i şer' ü

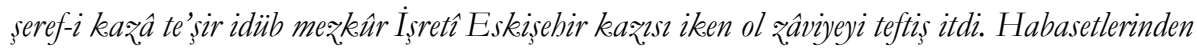
mâl-ı vakefa gadr ü hyânetleri ve ol ebl-i cenâbetlerün cebâbetlerinde niçe cinâyetleri zâhir olub tafsil-i abvâl ma'rûz-ı arsa-i pâdişâh-ı 'adâlet-meâl oldukda buyurdılar ki ol mahâl mescîd ü menâr ve câygâh-ı 'ilm-i pür-envâr olup ol battal-hâne medrese-i erbâb-ı iștigâl olub abdalun abvâli 'ilme ibdâl olna. Tedrîs ü fetvâ bid'at ü hevâya ni'me'l-bedel ola ve ol buk'a keserâbin biki'atin iken menba'-ı âb-ı 'ilm ü amel ola"'

Bu manada resmi evrak ile bireysel metinlerin dili arasında bir fark nazarı dikkati çekmekle beraber Seyyid Gāzi'de icrâ edilen mahiye merasimleri çerçevesinin hemen aynı kavramlarla izah edildiği dikkat çekmektedir. Hem resmi evrakta hem de Âşık Çelebi'nin anlatısında mahiye zamanında bendir seslerinin etkin olarak duyulduğu

17 Âşık Çelebi, Meşâirü̉ss-Şu'arâ, İnceleme-Metin, C. 2, Haz. Filiz Kılıç, İstanbul 2010, s. 1081-1082. 
anlaşılmaktadır. Yine her iki metinde de bu kalabalıktan kaynaklanmak üzere çevrede bazı bireysel güvenlik ihlallerinin, mala ve cana kasd anlamında bazı vakaların yaşandığı da anlaşılmaktadır.

Sonuç olarak Seyyid Gāzi Zâviyesi, başlangıçta tamamen Kalenderi ve Abdalların kutsal mekânı olarak gelişmiş iken, XVI. yüzyılın sonlarından itibaren, bir dönem devletin nezaretinde sünni alg1 ile ıslah edilmeye çalışılmış ise de zamanla eski geleneklerin yeniden su üzerine çıktığı, özellikle XVII. yüzyıldan sonra Bektaşiliğin de kutsal merkezlerinden birisi olarak dikkat çeken bir kurum olarak varlığını devam ettirmiştir. Bütün bu eksende sünni kesimlerin de buraya ilgisiz kaldıkları söylenemez.

Osmanlı merkez yönetimi gerek Seyyid Gāzi'yi gerekse bu kurumu aziz olarak kabul edip hukukunu ve gelirlerini korumayı gözetirken kurum içerisinde gelişen ve toplumun ekser kesiminin çok da hoş görmeyeceği uygulamaları kesin kez yasaklamaktan da geri durmamıştır. 


\section{Arşiv Belgeleri:}

BOA. MD. (Mühimme Defterleri), 69, 73.

BOA. MAD (Maliyeden Müdevver Defterler), 27.

\section{Kaynaklar ve Araştırmalar:}

AHMET REFIKK (1932). On Altıncı Asırda Rafizilik Bektaşilik, İstanbul.

AY, Resul (2015). "Anadolu ve Rumeli'de Derviş Seyahatleri ve Kırsal Toplum İçin Gördügü İşlevler (13-15. Yüzylllar)”, Ötekilerin Peşinde, Ahmet Yaşar Ocak’a Armağan, Haz. Mehmet Öz-Fatih Yeşil, İstanbul 2015, ss. 303-315.

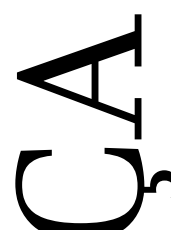

ÂŞIK ÇELEBİ (2010). Meşâirü’ş-Şu’arâ, İnceleme-Metin, Haz. Filiz Kılıç, İstanbul. COŞAN, Leyla (2009). "Georgius de Hungaria ve Türkler Hakkındaki Değerlendirmelerine Bir Bakış", Semahat Yüksel Armağan Kitabı, Feruzan Gündoğar, Güler Mungan; Cemal Yıldız, Ankara, ss. 198-207.

ELÇİ, Armağan (1999). "Semah Geleneğinin Uygulanması", Gāzi Üniversitesi Hacı Bektaş Veli Dergisi, 12 1-23. (Derginin bu sayısının sayfa numaraları yoktur.).

ERSAL, Mehmet-Bülent Akın, (2016). "Alevi Geleneğinde Yaşayan Yunus Emre”, Uluslararası Yunus Emre Sempozyumu Bildirileri, Edt. Ünal Şenel, Manisa ss. 163199.

FAROQHI, Suraiya (1981). "Seyyid Gazi Revisited: The Foundation as Seen Through Sixteenth and Seventeenth-Century Documents", Turcica, Revue D’Etudes Turques, Tome XIII, Paris, ss. 90-122.

GÖLPINARLI, Abdülbaki (1995). “Otman Baba Vilayet-Nâmesi”, Journal of Turkish Studies, Vol. 19/1995, ss. LV-CV.

KÖPRÜLÜ, Fuad (1984), Türk Edebiyatında İlk Mutasavvıflar, Ankara.

MACARISTANLI GYÖRGY, (2009). Türkler, Türklerin Gelenekleri, Görenekleri ve Hinlikleri Üzerine İnceleme, Michel Balivet, Türk Korkusu, çev. Lale Arslan Özcan, İstanbul.

MELIKOF İrene (1993). "Alevi Adetleri Üzerine Notlar, Bazı Orta-Anadolu Kutlamaları Dolayısıyla”, İrene Melikof, Uyur İdik Uyardılar, Alevilik Bektaşilik Araştırmaları, trc. Turan Alptekin, İstanbul, ss. 81-87.

(1997). Anadolu Alevilerinin Bazı Törenleri Üzerine”, Yabancı Araştırmacılar Gözüyle Alevilik-Tuttum Aynayı Yüzüme Ali Göründü Gözüme, çev. İlhan Cem Erseven, İstanbul, ss. 61-64.

MENZEL, Theodor (1925). "Das Bektaschi Klöster Sejjid Gāzi”, Mitteilungen des Seminars für Orientalische Sprachen, 28, ss. 92-125.

OCAK, Ahmet Yaşar (1992). Osmanlı İmparatorluğunda Marjinal Sufilik: Kalenderîler (XIV-XVII. Yüzyıllar) Ankara.

ÖNEL, Mehmet Naci (2003). "Dağ Kültü, Eren Kültü ve Şenliklerinin Muğla'daki Yansımalarr", Bilig, Bahar 2003, say1: 25, ss. 99-124.

“Battal Gāzi”, TDV. İA, V, 204-205.

ÖZCAN, Altay Tayfun (2013). “Macaristanlı Georgius'a Göre XV. Yüzyll 
Türkiye'sindeki Heterodoks Kesim”, Diyalog, Interkulturelle Zeitschrift für Germanistik 2013/2, ss. 110-120.

SAY Yağmur (ty.) Seyyîd Battal Gazi ve Külliyesi, ty. İstanbul.

YENIŞEHIRLIOĞLU, Filiz (2008). "The Tekke of Seyyid Battal Gāzi”, Anadolu ve Çevresinde Ortaçağ, ed. Mine Kadiroğlu, Ankara ss. 121-164.

YÜREKLI, Zeynep (2005). Legend and Architecture in Ottoman Empire: The Shrine of Seyyid Gāzi and Hacı Bektaş (Ph.D. diss., Harvard University).

(2012). Arhitecture and Hagiography in the Ottoman Empire, The Politics of Bektashi Shrines in the Classical Age, New York. 
